\title{
An Effort to Isolate Mycobacterium bovis from Environmental Substrates during Investigations of Bovine Tuberculosis Transmission Sites (Cattle Farms and Wildlife Areas) in Michigan, USA
}

\author{
Amanda E. Fine, ${ }^{1,2}$ Daniel J. O'Brien, ${ }^{3}$ Scott R. Winterstein, ${ }^{4}$ and John B. Kaneene ${ }^{1}$ \\ ${ }^{1}$ Center for Comparative Epidemiology, Department of Large Animal Clinical Sciences, College of Veterinary Medicine, \\ Michigan State University, East Lansing, MI 48824-1314, USA \\ ${ }^{2}$ Wildlife Conservation Society, Mongolia Country Program, P.O. Box 485, Post Office 38, Ulaanbaatar 211238, Mongolia \\ ${ }^{3}$ Wildlife Disease Laboratory, Michigan Department of Natural Resources, 4125 Beaumont Road, Lansing, MI 48910-8106, USA \\ ${ }^{4}$ Department of Fisheries and Wildlife, College of Agriculture and Natural Resources, Michigan State University, 13 Natural Resources, \\ East Lansing, MI 48824, USA
}

Correspondence should be addressed to John B. Kaneene, kaneene@cvm.msu.edu

Received 9 June 2011; Accepted 14 July 2011

Academic Editors: A. Unver and W. Yang

Copyright (C) 2011 Amanda E. Fine et al. This is an open access article distributed under the Creative Commons Attribution License, which permits unrestricted use, distribution, and reproduction in any medium, provided the original work is properly cited.

\begin{abstract}
Deer movements on cattle farms, wildlife feeding, and livestock management practices in Michigan are thought to create opportunities for indirect transmission of Mycobacterium bovis via environmental substrates. To confirm the presence of viable M. bovis in the environment, substrates were collected from 13 farms with culture-confirmed M. bovis in cattle and 5 sites with high prevalence of $M$. bovis in free-ranging deer. None of the samples processed for mycobacterial culture were positive for M. bovis. Agent, host, and landscape-level factors decrease the probability of detecting M. bovis in the environment using conventional mycobacterial culture. Molecular techniques that increase the probability of $M$. bovis detection in environmental substrates should be applied to known sites of M. bovis transmission in Michigan. In the interim, epidemiological investigations informed by experimental studies will be most effective in characterizing $M$. bovis persistence in the environment and its role in the indirect interspecies transmission of M. bovis.
\end{abstract}

\section{Introduction}

The State of Michigan lost its United States Department of Agriculture designation as "Free from Tuberculosis (TB)" in 2000. This reversal of the State's TB Free status, originally achieved in 1979, was the result of the detection of bovine TB in Michigan cattle in 1998 and confirmation of the establishment of bovine TB in free-ranging white-tailed deer (Odocoileus virginianus) in northeast lower Michigan in 1995 [1]. Fifty farms with Mycobacterium bovis infected cattle have been detected in Michigan since intensive surveillance for TB in livestock was reinitiated in 1998 [2].

The occurrence of bovine TB in cattle and whitetailed deer in Michigan has a similar temporal and spatial distribution [3]. In addition, DNA fingerprinting techniques have revealed that cattle and deer are infected with an identical strain of $M$. bovis [4]. Evidence supports interspecies transmission of M. bovis from the wildlife reservoir (whitetailed deer) to cattle which is assumed to occur through indirect means via shared feed [5]. White-tailed deer are the presumed source of $M$. bovis infection in cattle in over $50 \%$ of the herds identified as TB-positive in Michigan [6]. Disease transmission in these instances is thought to occur in the absence of close contact between cattle and deer, since noseto-nose contact between the two species is rarely observed [7].

Bovine TB in Michigan's white-tailed deer population has been characterized as having an endemic focus within 
the five-country area of Presque Isle, Montmorency, Alpena, Oscoda, and Alcona counties, where $97 \%$ of the TB-positive deer have been found $[6,8,9]$. The detection of bovine TB in Michigan cattle has been concentrated in the same area of Michigan. This region of the State, encompassing the five counties that make up the endemic focus of bovine TB in deer in addition to Antrim, Charlevoix, Cheboygan, Crawford, Emmet, Otsego, and portions of Iosco and Ogemaw counties have been designated as "infected" with bovine tuberculosis and classified as "modified accredited" under the guidelines of the Federal Bovine Tuberculosis Eradication Uniform Methods and Rules [10].

The overall goal of this study was to perform targeted sampling of environmental substrates in known bovine TB transmission sites and apply sample processing procedures developed for processing environmental samples for $M$. bovis detection in an effort to characterize the persistence of $M$. bovis in the environment and the role of indirect transmission of M. bovis in the epidemiology of bovine TB in Michigan. The study attempted to detect M. bovis in the environment and determine whether or not it could survive for sufficient lengths of time to serve as a source of infection for cattle and/or wild deer. The work compliments that published by Witmer et al. [11] which focused on sampling a range of wildlife species found on farms and in wildlife areas in the bovine TB outbreak region of Michigan in an attempt to identify a wildlife reservoir for M. bovis other than whitetailed deer.

\section{Materials and Methods}

2.1. Identification of Bovine Tuberculosis Transmission Sites. Potential sites of bovine TB transmission were defined as Michigan cattle farms with confirmed $M$. bovis infection or Michigan townships with the highest recorded apparent prevalence of $M$. bovis in free-ranging white-tailed deer. Bovine TB-positive cattle farms were those farms with a culture-confirmed case of $M$. bovis infection identified through the State and Federal bovine $\mathrm{TB}$ surveillance program. Cattle farms identified as bovine TB-positive were presumed to be sites of bovine $\mathrm{TB}$ transmission. All of the farms investigated were located in the region of the State of Michigan designated as "infected" with bovine tuberculosis and classified as "modified accredited" under the guidelines of the Federal Bovine Tuberculosis Eradication Uniform Methods and Rules [10]. The "modified accredited" zone at the time encompassed Alcona, Alpena, Antrim, Charlevoix, Cheboygan, Crawford, Emmet, Montmorency, Oscoda, Otsego, and Presque Isle counties, and those portions of Iosco and Ogemaw counties that are north of the southernmost boundaries of the Huron National Forest and the Au Sable State Forest (Figure 1).

Between June 2002 and September 2004, 12 cattle farms in Michigan were declared bovine tuberculosis positive by State (Michigan Department of Agriculture) and Federal (USDA/APHIS/Veterinary Services) animal health officials. DNA fingerprinting of the M. bovis isolates associated with bovine tuberculosis (TB) on all of these farms was confirmed as the Michigan M. bovis strain, first characterized in the state in 1999. Access to collect environmental samples potentially contaminated with $M$. bovis was granted for 11 of the 12 farms. Two additional cattle farms, one identified as bovine TB-positive in 2000 and the other identified in 2001, were also investigated at the request of the farm owners.

Farm investigations were scheduled within an average of two months of the officially recorded bovine TB-positive date for each of the farms identified between June 2002 and September 2004 (Table 1). One farm was investigated 10 days before the official TB-positive date, and the remaining 10 farms were investigated after their officially recorded TB-positive date. The average time between environmental sampling and the official TB-positive date was 56.18 days (average deviation $=27.47$; median $=55 ; \max =107 ; \min$ $=10)$. The two farms identified in 2000 and 2001 were investigated 929 days and 612 days, respectively, after the officially recorded TB-positive date for each farm. The cattle from 9 of the 10 farms identified as TB-positive between 2002 and 2004 were depopulated. The investigation and sampling of the TB-positive farms was accomplished before the cattle were depopulated on five farms and after the cattle were depopulated for the remaining 4 farms (Table 1). The average time between farm sampling and cattle depopulation was 32.67 days (average deviation $=11.56 ;$ median $=31 ; \max =$ 55 ; $\min =7$ ).

Wildlife areas selected for sampling were all within the 5 Michigan townships with the highest apparent prevalence of bovine TB in white-tailed deer. The wildlife sites sampled were either the capture locations of M. bovis-infected small mammals, primarily raccoons (Procyon lotor) and opossums (Didelphis virginiana) or areas of known white-tailed deer congregation. The areas of known white-tailed deer congregation selected were all located in the region designated as the "core" of the endemic area of bovine TB currently affecting white-tailed deer [6]. The "core" is defined by the administrative boundaries of the Michigan Department of Natural Resources Deer Management Unit number 452 (Figure 2).

2.2. Sampling Site and Substrate Selection. Specific substrates targeted for collection within the sites were selected based on environmental and farm management factors identified as risk factors for bovine TB infection on Michigan cattle farms [12] and previous evaluations of the practice of supplemental feeding of white-tailed deer $[1,8,13]$. On cattle farms, a structured questionnaire with farm managers and a farm walk-through were used to identify approximately 20 sampling locations per farm. Targeted sites included those with evidence of animal concentration (mixed, and single species), feed and water sites with open access to livestock and wildlife, the location within the farm of the infected cattle if known (i.e. pasture, pen or stall), and sites of wildlife observations within the farm borders, including pastures and woodlots. Substrates from the specified locations selected for sampling included feed (hay, grain and silage), pasture grass, soil, fecal material, bedding, and water. Figure 3 depicts three sites selected for sampling on bovine TB-positive farms.

The locations for environmental sampling within the wildlife areas selected as potential bovine TB transmission 


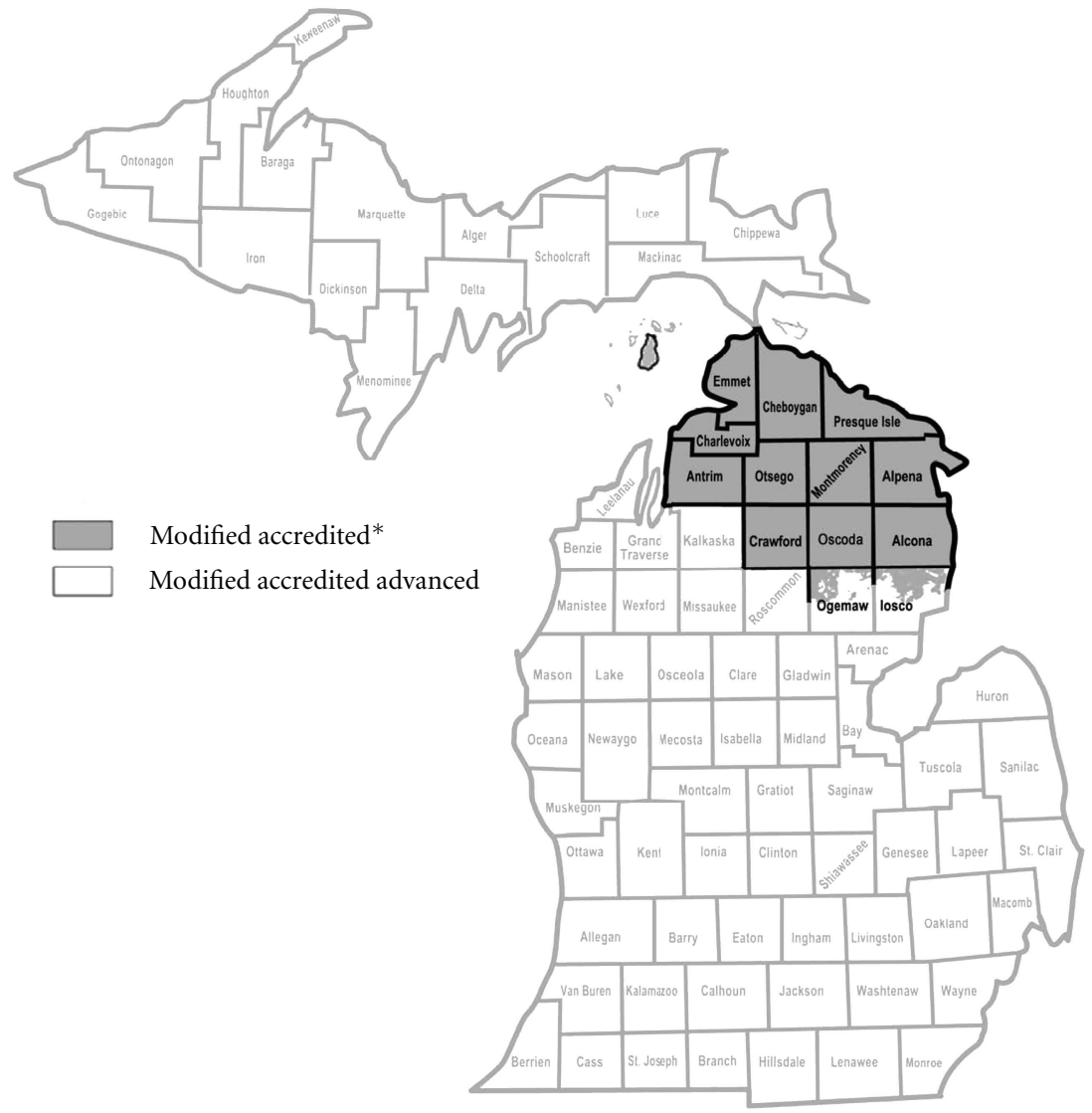

Figure 1: Map of Michigan indicating the Bovine Tuberculosis State Status Designations: (1) modified accredited (infected zone) and (2) modified accredited advanced (disease-free zone). Source: Michigan Department of Agriculture, http://www.michigan.gov/bovinetb.

sites were identified with the assistance of wildlife biologists from the Michigan Department of Natural Resources (MDNR) and United States Department of Agriculture (USDA), Animal Plant Health Inspection Service (APHIS), Wildlife Services (WS). Deeryards (naturally sheltered areas used by deer during severe winters with significant snow fall), deer feeding sites, and adjacent areas of open water were selected within the townships identified as having a high prevalence of bovine TB. The area surrounding the trap location of small mammals, primarily raccoons and opossums, identified as TB-positive was surveyed to identify specific substrates for sampling. Substrates selected for sampling from both white-tailed deer and small mammal sites included fecal material, soil, vegetation, and water. Figure 4 depicts three sites selected for sampling in the wildlife bovine TB transmission areas.

2.3. Sample Collection. Approximately 500 grams of substrate was collected from each of the sampling locations identified. Disposable latex gloves or a cleaned and betadinedisinfected shovel was used to collect each sample to prevent cross-contamination. Water samples were collected in 0.5 liter sterile plastic bottles and capped. All other substrates were placed in large capacity Whirl-Pak bags and sealed. The sample containers were labeled with a unique identification number. Additional data corresponding to the sample identification number and a description of the sampling site were collected and recorded on field data sheets. Recorded data included a description of the sample collected, a description and the GPS coordinates of the sample collection location, and a digital photograph of the sampling site. Samples were stored in an insulated cooler surrounded with cold packs. They were transported by vehicle to the Biosafety Level III laboratory at Michigan State University within 8 hours of collection. The samples were stored at $4^{\circ} \mathrm{C}$ for 12 hours before processing.

2.4. Sample Processing. All samples were processed using procedures developed for processing environmental samples for mycobacterial culture that maximized $M$. bovis recovery rates and minimized the level of culture contamination with competing organisms [14]. The procedure developed incorporated the use of CB-18 TB Culture Kit with Lytic Decon II (Integrated Research Technology, LLC, Quest Diagnostics Inc., Baltimore, Md, USA). The CB-18 TB Culture Kit with Lytic Decon II (Integrated Research Technology, LLC) is a commercially available set of reagents and instructions for processing specimens for the detection of mycobacteria 
TABle 1: Time lag between farm investigation (environmental sampling), official TB-positive date, and date of cattle depopulation. Farms identified as TB+ in 2000 and 2001 (nos. 105 and 106) were not included in this analysis.

\begin{tabular}{|c|c|c|c|c|c|}
\hline Farm number & $\mathrm{TB}+$ date & Depopulation date & Sampling date & $\begin{array}{c}\text { TB+ to sampling } \\
\text { days }\end{array}$ & $\begin{array}{c}\text { Depopulation to } \\
\text { sampling days }\end{array}$ \\
\hline 101 & $09 / 20 / 02$ & $10 / 02 / 01$ & $09 / 10 / 02$ & -10 & -22 \\
\hline 102 & $07 / 17 / 02$ & $09 / 17 / 02$ & 09/10/02 & 55 & -7 \\
\hline 103 & $07 / 16 / 02$ & $08 / 21 / 02$ & $09 / 13 / 02$ & 59 & 23 \\
\hline 104 & $06 / 12 / 02$ & $10 / 29 / 02$ & $09 / 27 / 02$ & 107 & -32 \\
\hline 107 & $01 / 09 / 03$ & $03 / 31 / 03$ & $02 / 28 / 03$ & 50 & -31 \\
\hline 108 & $11 / 27 / 02$ & & $03 / 04 / 03$ & 97 & Not depopulated \\
\hline 109 & $01 / 27 / 03$ & $03 / 11 / 03$ & $05 / 05 / 03$ & 98 & 55 \\
\hline 110 & $05 / 27 / 03$ & $06 / 03 / 03$ & $07 / 02 / 03$ & 36 & 29 \\
\hline 111 & $11 / 10 / 03$ & $01 / 21 / 04$ & $12 / 02 / 03$ & 22 & -50 \\
\hline 112 & $12 / 23 / 03$ & & 03/03/04 & 71 & Not depopulated \\
\hline \multirow[t]{2}{*}{113} & $08 / 20 / 04$ & $07 / 19 / 04$ & $09 / 02 / 04$ & 13 & 45 \\
\hline & & & Average: & 56.18 days & 32.67 days \\
\hline
\end{tabular}

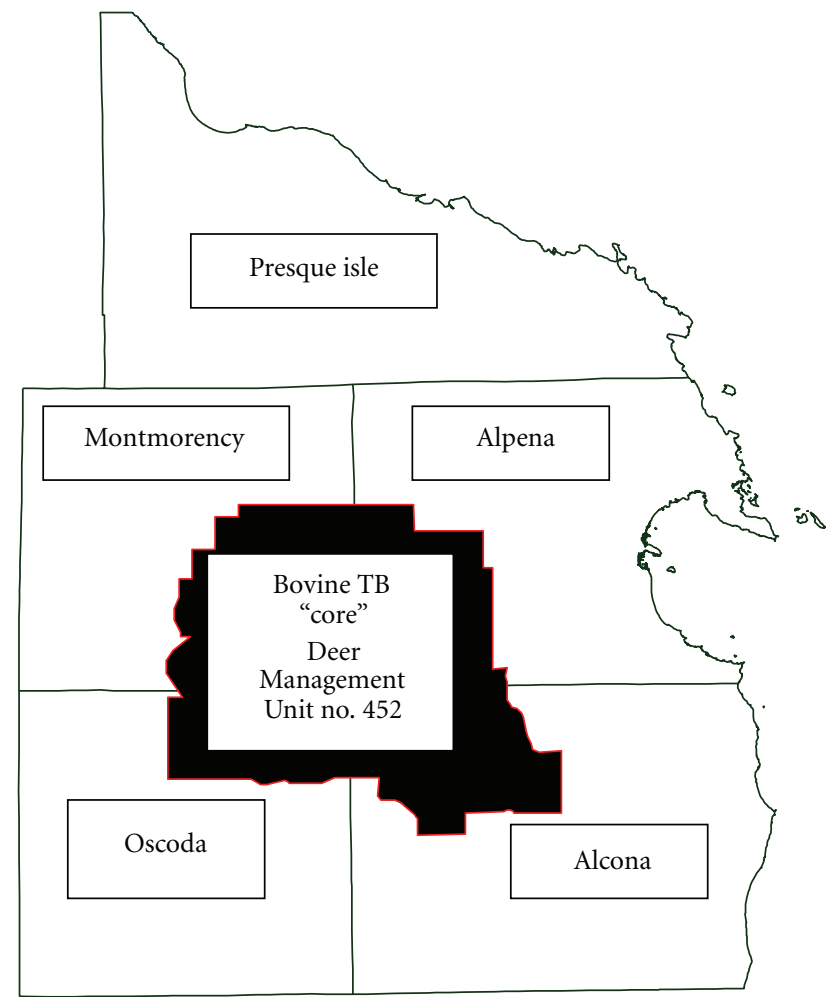

FIgURE 2: Map of the bovine TB "core" area within the counties of Montmorency, Alpena, Oscoda, and Alcona, Michigan.

by culture. The kit contains $\mathrm{C}_{18}$-Carboxypropylbetaine (CB18), a zwitterionic detergent that replaces $\mathrm{NaOH}$ acid wash in the decontamination step and is also thought to decrease surface tension and counteract the natural buoyancy of mycobacteria and facilitate the more efficient collection of the bacilli [15]. The kit also contains the components of a resuspension buffer with lecithin and a mixture of lytic enzymes (lysozyme, zymolyase, Cytophaga, and Trichoderma extracts). The resuspension buffer is added to the sample sediment before the inoculation of mycobacteria isolation media to reduce contamination with competing organisms [16].

A series of studies using typical environmental substrates (soil, hay, and water) experimentally inoculated, or spiked, with the Michigan strain of M. bovis were performed in the mobile Biosafety Level III (BL3) Laboratory on the campus of Michigan State University (MSU) in advance of the investigations of bovine TB transmission sites described in this paper to develop the procedures for processing environmental samples for mycobacterial culture. The minimum detection level for the sample processing procedures developed was determined to be 120 colony forming units (CFUs) of $M$. bovis present in the volume of environmental substrate ( $5 \mathrm{gm}$ of solid substrates and $7.5 \mathrm{~mL}$ of water) processed in the experiments [14]. This volume of substrate was used as the standard volume of substrate processed from environmental samples collected from the field. The experimental studies performed to develop the procedures for processing environmental samples also recorded the rates of mycobacterial culture contamination with competing organisms in $M$. bovis spiked samples processed with conventional $\mathrm{NaOH}$ methods as compared to those presented in this paper which incorporate the CB-18 TB Culture Kit with Lytic Decon II. The odds of contamination in $\mathrm{NaOH}$-processed $M$. bovis inoculated environmental substrates that were not presterilized were 11 times that of the same substrates processed with the CB-18 method (OR $=11.0$; 95\% C.I. $(3.2,37.9)$ ) [14].

In the BL3 Laboratory, environmental samples collected during investigations of bovine $\mathrm{TB}$ transmission sites were thoroughly mixed by shaking or swirling the contents within their original sample collection containers and approximately $5 \mathrm{gm}$ of the solid substrates and $7.5 \mathrm{~mL}$ of water were transferred for further processing. Soil and fecal samples were placed in individual $7.6 \mathrm{~cm} \times 17.8 \mathrm{~cm}$ Whirl-Pak bags. Feed and vegetation samples were chopped with scissors 


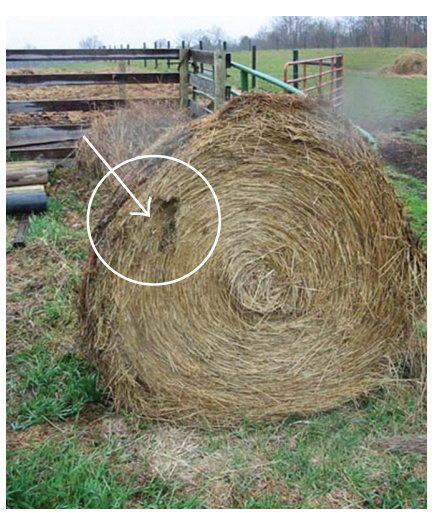

(a)

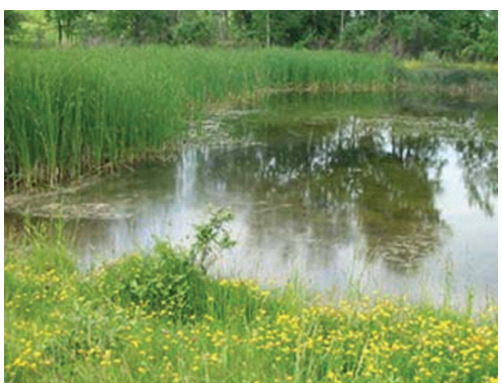

(b)

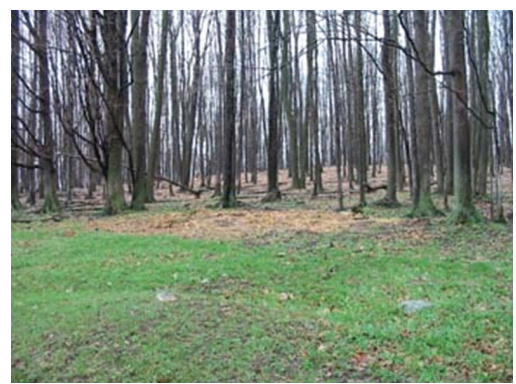

(c)

FIGURE 3: Three photographs of sampling locations selected during investigations of bovine tuberculosis-positive cattle farms: (a) an unprotected hay bale with evidence of deer feeding activity; (b) a pond in a pasture to which both deer and cattle have access; (c) an example of feeding cattle hay on the ground in the woods.

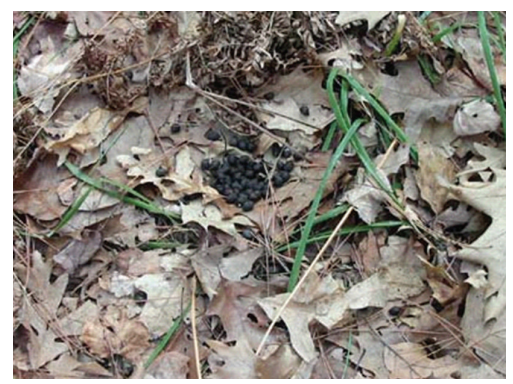

(a)

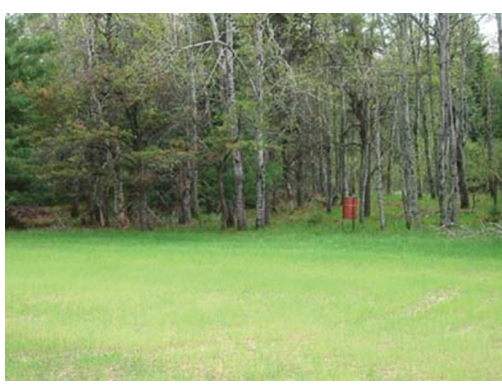

(b)

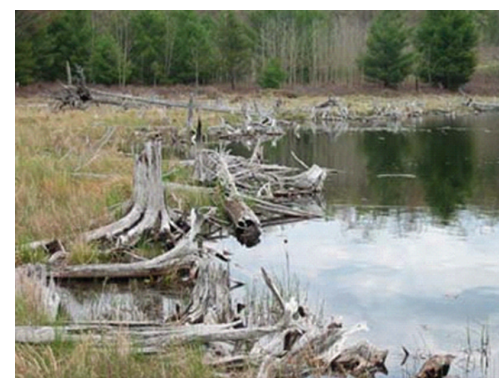

(c)

FIGURE 4: Three photographs of sites selected for sampling in the wildlife bovine TB transmission areas: (a) an oak forest where deer fecal pellets were collected; (b) a deer feeder and a plot of forage planted for deer; (c) a pond near the trap location of a bovine TB-positive (opossum or raccoon).

when necessary and placed in individual sterilized Ball pint $(473 \mathrm{~mL})$ regular mason jars. Water samples were transferred to individual $50 \mathrm{~mL}$ conical centrifuge tubes.

Sterile water $(7.5 \mathrm{~mL})$ and $5 \mathrm{~mL}$ of liquefaction solution (trisodium citrate dehydrate and $\mathrm{N}$-acetyl-L-cysteine or NALC) were added to the solid substrates. Samples were then pulverized and homogenized by placing the Whirl-Pak bags in a Stomacher 80 laboratory blender for 30 seconds, and securing a blade unit and gasket on the jars, inverting and blending them for 30 seconds on high with a household blender. Five $\mathrm{mL}$ of liquefaction solution were added to the water samples, and they were mixed on high for 30 seconds with a vortex machine.

The samples were placed upright and allowed to settle for 30 minutes. The top $5 \mathrm{~mL}$ of fluid from each sample was removed and transferred to a $50 \mathrm{~mL}$ conical tube containing $10 \mathrm{~mL}$ of Decontamination Solution (20X Tris-citrate Buffer, CB-18 Stock, or NALC and water). Samples were mixed with a vortex machine and incubated at $37^{\circ} \mathrm{C}$ for 75 minutes. Sterile water was added to the $50 \mathrm{~mL}$ mark on each tube, mixed and centrifuged at 3,000 g for 20 minutes. Pelletcontaining tubes were decanted completely. A pipette was used to remove all but $1-3 \mathrm{~mL}$ of liquid from samples without a visible pellet. The pellet was resuspended in the supernatant backwash. One $\mathrm{mL}$ of sterile water was added and mixed. A $0.5 \mathrm{~mL}$ sample was transferred to a $2.0 \mathrm{~mL}$ labeled cryogenic vial and frozen at $-80^{\circ} \mathrm{C}$. One $\mathrm{mL}$ of 2X Resuspension Solution (10X-Enzyme Stock-Trichoderma harzianum extract, lysozyme and Lysobacter extract and NALC) was added to each sample, and they were incubated for 45 minutes at $37^{\circ} \mathrm{C}$.

2.5. Mycobacterial Culture and Isolation. CB-18-processed samples were inoculated onto solid media slants and plates containing modified Middlebrook 7H11 agar (BectonDickinson) with sodium pyruvate (Diagnostic Center for Population and Animal Health, Lansing, Mich, USA) and 7H11 Selective plates (Becton-Dickinson). Solid media slants and plates were incubated at $37^{\circ} \mathrm{C}$ for $8-12$ weeks and examined weekly for colony formation. Positive mycobacterial cultures and colonies on solid media were subjected to an acid-fast smear analysis to confirm the presence of acidfast bacteria using standard protocols for slide preparation, staining, and examination [17]. Acid-fast-positive isolates were identified to the Mycobacterium tuberculosis complex species group using a genetic probe (AccuProbe, GenProbe, San Diego, Calif, USA). Biochemical tests and highperformance liquid chromatography were performed by 
the Michigan Department of Community Health (MDCH) Tuberculosis/Mycology Laboratory to speciate non-M. tuberculosis complex mycobacteria or to differentiate between Mycobacterium bovis and other members of the M. tuberculosis complex.

2.6. Statistical Analysis. Excel spreadsheets and statistical functions (AVERAGE, AVEDEV, MEDIAN, MAX, and MIN) were used to generate simple descriptive statistics characterizing the bovine tuberculosis transmission sites and the specific locations identified as sites of potential environmental contamination with Mycobacterium bovis (Excel, Microsoft Office XP Professional). Excel spreadsheets were also used to record mycobacterial culture results and summarize the data on the isolation of acid-fast bacteria and the presence or absence of contamination with competing organisms. Comparisons between mycobacterial culture result, substrate type, and presence or absence of contamination with competing organisms were made using the Cochran-MantelHaenszel test for $n$-way cross-tabulation tables and the SAS software program (Proc Freq; Tables/CMH, SAS version 9.0, Cary N.C.: SAS Institute, Inc.).

\section{Results}

3.1. Cattle Farms: General Characteristics and Farm Management Practices. Of the thirteen bovine tuberculosis cattle farms investigated, four were dairy operations, seven were beef cow/calf operations, one was a small beef feeder operation, and one was a combination cow/calf and feeder operation. The number of adult cattle on the farms ranged from 14 to 239 and averaged 74 . The average size of the farm properties was 251 acres. Only 1 farm reported fenceline contact with another cattle farm. Approximately half of farms that were identified as bovine TB-positive between June 2000 and September 2004 purchased 100\% of their cattle from outside sources. The majority of the farms did not raise any other kind of livestock, with the exception of chickens, and all but one reported the presence of pet dogs and cats on the farm (Table 2).

Full farm investigations (interviews with farm owners or primarily cattle managers and farm walkthrough) were performed on the first 12 farms sampled. USDA/APHIS/WS personnel collected environmental samples from the 13th farm, but only very general farm characteristics were recorded. Although 10 of the 12 farms had cattle housing (barn, feedlot, or barn yard) facilities, cattle spent more than $50 \%$ of their time outside on 9 of the 12 farms. The three farms on which cattle spent more than $50 \%$ of their time inside were dairy herds. Only 1 farm, a dairy, never fed cows outside. Cattle on all of the farms had access to water sources outside, and on 10 of the farms cattle had access to surface water (ponds, streams, or water ways). Hay was provided to cattle in a feeder on 4 of the farms, but it was also provided on the ground on 2 of these. Ten of the 12 farms provided hay to their cattle outside on the ground. A summary of the cattle management practices on each of the farms is summarized in Table 3(a).
An examination of feed storage and general fencing practices on the farms revealed that hay (round bales) were stored outside and unprotected on 8 of the 12 farms. Round bales of hay were stored in the fields, along fencerows or in the woods on 4 of the farms. Five of the farms used some barbed wire, and 9 of the farms used electric fencing. Two of the farms had "deer proof" fencing around their hay that had been installed through a USAID/APHIS/WS program after their cattle were identified as bovine TB-positive. A summary of the fencing and feed storage practices is provided in Table 3(b).

All of the farmers interviewed reported observing deer on their property. All but one of the 12 farms reported observing deer in their cattle pastures, and all 12 farms reported observing deer feeding on either their pastures or crop fields. Deer were not observed drinking water from outdoor tanks but 5 of the farms reported observing evidence of deer using the same open water sources accessible to cattle on the farm. Six of the 12 farms reported observing deer feeding on harvested hay intended for cattle, and all but 1 farm reported the presence of land features preferred by deer (orchards or cedar swamps) on or adjacent to their property (Table 3(c)). Producers on all farms surveyed reported observations of wildlife other than deer. The species observed included raccoons (Procyon lotor), opossum (Didelphis virginiana), red fox (Vulpes vulpes), coyote (Canis latrans), turkeys (Meleagris gallopavo), striped skunks (Mephitis mephitis), bobcats (Felis rufus), black bears (Ursus americanus), and porcupine (Erethizon dorsatum).

3.2. Cattle Farms (Samples Collected). A total of 409 samples were collected from 13 farms. Approximately 20 sites were selected for sampling on each farm. One sample was collected per site for the first 10 farms. An effort was made to intensify sampling on the final two farms and more samples were collected per site. A total of 140 samples were collected from farm 112, and a total of 52 samples were collected from farm 113 (Table 4).

3.3. Wildlife Areas (Samples Collected). A total of 97 samples were collected from 5 wildlife areas. Approximately 20 locations were selected for sampling in each wildlife area, and approximately 1 sample was collected per site. An attempt was made to distribute the sampling across substrate type (Table 5).

3.3.1. Mycobacterium bovis Culture Results. None of the samples collected from the bovine TB-positive farms were positive for Mycobacterium bovis based on mycobacterial culture. A number of acid-fast organisms were isolated but further testing revealed that none of these were members of the M. tuberculosis complex (Table 4). Acid-fast organisms were most commonly isolated from soil, vegetation, manure, and cattle feed samples, but an association between the isolation of acid-fast bacteria and sample type was not found (Mantel-Haenszel $X^{2}=0.04$; degree freedom $=1$; $P$ value $=0.84)$. Samples processed from wildlife areas produced similar results. Acid-fast bacteria were isolated 
TABLE 2: General characteristics of bovine TB-positive farms selected for environmental sampling.

\begin{tabular}{|c|c|c|c|c|c|c|c|}
\hline Farm number & Farm type & $\begin{array}{l}\text { Herd size } \\
\text { No. Adults }\end{array}$ & $\begin{array}{c}\text { Farm size } \\
\text { Acres }\end{array}$ & $\%$ Purchased & Fence line contact & Other livestock & $\begin{array}{c}\text { Pets } \\
\text { Dogs/Cats }\end{array}$ \\
\hline 101 & Beef feeder & 31 & 110 & 100 & No & No & Yes \\
\hline 102 & Dairy & 79 & 428 & 0 & No & No & Yes \\
\hline 103 & Cow/calf & 37 & 102 & 100 & No & No & Yes \\
\hline 104 & Cow/calf & 40 & 128 & 100 & No & No & No \\
\hline 105 & Cow/calf & 108 & 330 & - - - - * & Yes & No & Yes \\
\hline 106 & Cow/calf & 103 & 540 & - - - - * & No & Horses & Yes \\
\hline 107 & Cow/calf & 23 & 188 & 5 & No & Chickens & Yes \\
\hline 108 & Dairy & 239 & 500 & 100 & No & No & Yes \\
\hline 109 & Cow/calf & 19 & 80 & $>50$ & No & Chickens & Yes \\
\hline 110 & Cow/calf & 48 & 300 & 25 & No & Horses/sheep & Yes \\
\hline 111 & Cow/calf-feeder & 14 & 244 & $<5$ & No & Chickens & Yes \\
\hline 112 & Dairy & 68 & 65 & $<5$ & No & No & Yes \\
\hline \multirow[t]{2}{*}{113} & Dairy & 148 & & & & & \\
\hline & Average: & 73.62 & 251.25 & & & & \\
\hline
\end{tabular}

*Farm 105 and 106 were TB positive before the study period.

TABLE 3: A summary of (a) cattle management practices; (b) feed storage and fencing practices; and (c) reported white-tailed deer movements on bovine TB-positive farms selected for environmental sampling.

(a)

\begin{tabular}{lcccccccc}
\hline A & $\begin{array}{c}\text { Housing } \\
\text { barn/lot }\end{array}$ & $>50 \%$ outside & Feed outdoors & $\begin{array}{c}\text { Feed outdoors } \\
\text { only }\end{array}$ & Hay feeder & $\begin{array}{c}\text { Hay } \\
\text { ground }\end{array}$ & $\begin{array}{c}\text { Water tank } \\
\text { outdoors }\end{array}$ & $\begin{array}{c}\text { Water open } \\
\text { outdoors }\end{array}$ \\
\hline$\%$ yes: & $83 \%$ & $75 \%$ & $92 \%$ & $58 \%$ & $33 \%$ & $83 \%$ & $50 \%$ & $83 \%$ \\
\hline
\end{tabular}

(b)

\begin{tabular}{lccccc}
\hline B & $\begin{array}{c}\text { Hay unprotected } \\
\text { outdoors }\end{array}$ & $\begin{array}{c}\text { Round bale } \\
\text { field/fence/woods }\end{array}$ & $\begin{array}{c}\text { Feed fenced } \\
\text { "deer proof" }\end{array}$ & $\begin{array}{c}\text { Cattle fencing } \\
\text { barbed }\end{array}$ & $\begin{array}{c}\text { Cattle fencing } \\
\text { electric }\end{array}$ \\
\hline \% yes: & $67 \%$ & $33 \%$ & $25 \%$ & $42 \%$ & $75 \%$ \\
\hline
\end{tabular}

(c)

\begin{tabular}{lcccccccc}
\hline $\mathrm{C}$ & In pasture & $\begin{array}{c}\text { Near cattle } \\
\text { housing }\end{array}$ & Near home & $\begin{array}{c}\text { Drinking } \\
\text { tank water }\end{array}$ & $\begin{array}{c}\text { Drinking open } \\
\text { water }\end{array}$ & $\begin{array}{c}\text { Feeding on } \\
\text { pasture/crop }\end{array}$ & Feeding on hay Deer preferred \\
habitat
\end{tabular}

TABLE 4: Mycobacterial culture results of environmental substrates collected from bovine tuberculosis-positive farms.

\begin{tabular}{lccc}
\hline & Total & AFB + (\%) & Contamination + (\%) \\
\hline Pasture and & 79 & $13(16 \%)$ & $15(19 \%)$ \\
vegetation & 75 & $13(17 \%)$ & $32(43 \%)$ \\
Soil & 78 & $2(3 \%)$ & $12(30 \%)$ \\
Open water & 50 & $5(10 \%)$ & $10(20 \%)$ \\
Hay & 10 & $3(30 \%)$ & $2(20 \%)$ \\
Cattle feed & 4 & $0(0 \%)$ & $0(0 \%)$ \\
Barn water & 22 & $0(0 \%)$ & $9(41 \%)$ \\
Bedding & 40 & $1(3 \%)$ & $12(30 \%)$ \\
Manure & 23 & $6(26 \%)$ & $12(52 \%)$ \\
Manure mix & 10 & $0(0 \%)$ & $4(40 \%)$ \\
Deer feces & 17 & $1(6 \%)$ & $3(18 \%)$ \\
Wildlife feces & 1 & $0(0 \%)$ & $0(0 \%)$ \\
Bear hair & 409 & $44(11 \%)$ & $111(27 \%)$ \\
\hline
\end{tabular}


TABLE 5: Mycobacterial culture results of environmental substrates collected from potential wildlife bovine tuberculosis transmission sites.

\begin{tabular}{lccc}
\hline & Total & AFB + (\%) & Contamination + (\%) \\
\hline $\begin{array}{l}\text { Pasture and } \\
\text { vegetation }\end{array}$ & 17 & $1(6 \%)$ & $4(24 \%)$ \\
Soil & 24 & $2(8 \%)$ & $5(21 \%)$ \\
Open water & 22 & $0(0 \%)$ & $0(0 \%)$ \\
Wildlife feces & 5 & $0(0 \%)$ & $1(20 \%)$ \\
Deer feces & 28 & $0(0 \%)$ & $0(0 \%)$ \\
Grain & 1 & $0(0 \%)$ & $1(100 \%)$ \\
\hline
\end{tabular}

from samples of soil and vegetation, but no significant associations between substrate type and acid-fast bacterial isolation were found. The isolates of the non-M. tuberculosis complex acid-fast bacteria that could be identified to species included M. fortuitum, M. avium, M. fortuitum-chelonae, and Mycobacterium sp. Group IV.

The prevalence of contamination (overgrowth of the cultures with mold and nonmycobacteria) was high. Twentyseven percent of the samples collected from bovine TBpositive farms (Table 4) and 11\% of the samples collected from wildlife areas (Table 5) were contaminated. Soil samples and substrates mixed with manure were most likely to be contaminated, but no significant association between sample substrate and the presence of contamination was found (Mantel-Haenszel $X^{2}=0.01$; degree freedom $=1 ; P$ value $=$ $0.92)$.

\section{Discussion}

Mycobacterium bovis, the causative agent of bovine TB, continues to circulate among cattle and white-tailed deer in Michigan. Over the two-year span of this study, from June 2002 until September 2004, 12 cattle farms in northern Lower Michigan were identified as bovine TB-positive (Michigan Department of Agriculture). The cattle herds identified as bovine TB-positive during this period were all in the USDA designated "Modified Accredited Zone" (Figure 1) where annual whole-herd bovine TB testing is required [10]. The farms identified, therefore, likely represent new bovine $\mathrm{TB}$ infection and relatively recent transmission events. The estimated prevalence of $M$. bovis within these herds was low and no evidence of disseminated disease in individual cattle was found, further supporting a relatively recent exposure to $M$. bovis. Similarly, on-going surveillance for bovine TB in the white-tailed deer population during the same period revealed an apparent prevalence fluctuating around $2.0 \%$ in animals originating in MDNR, Deer Management Unit no. 452, the endemic focus of bovine TB in white-tailed deer in the State (Figure 2) [9]. A number of the bovine TB-positive white-tailed deer identified during this routine surveillance were yearlings, indicating new infection and recent bovine TB transmission events.

It is generally accepted that $M$. bovis is transmitted within deer populations through a combination of direct and indirect means and within cattle herds, primarily through close contact and direct routes of disease transmission $[18,19]$. Interspecies transmission of bovine TB between white-tailed deer and cattle, however, likely occurs primarily through indirect routes of transmission since little evidence of direct contact between the species exists [7]. Despite evidence of on-going bovine TB transmission in northeast Michigan, this study failed to isolate Mycobacterium bovis from environmental substrates collected from bovine TBpositive farms and wildlife areas.

\subsection{Potential Sites of M. bovis Contamination of the Environment}

4.1.1. Bovine TB-Positive Farms. The general characteristics of the 13 bovine TB-positive farms selected for investigation and environmental sampling in this study were similar to those of the initial group of bovine TB-positive farms identified between 1998 and 2002 [3]. The majority of the farms were small beef cattle operations, and they were all located in northeast lower Michigan. Particular cattle management practices that have been identified as risk factors associated with tuberculosis on cattle farms in northeast Michigan in the past [12] and those that would facilitate the indirect transmission of bovine TB from deer to cattle via M. bovis contaminated substrates included (1) maintenance of cattle outside for more than $50 \%$ of the time outside $(75 \%$ of farms); (2) feeding cattle outside (92\%) and feeding cattle outside exclusively (58\%); (3) watering cattle outside with access to open water (streams, ponds, etc.) $(83 \%)$; (4) feeding cattle hay on the ground $(83 \%)$.

The practices outlined above are only a bovine TB risk to cattle if infected white-tailed deer in the area also have access to the hay, pasture, and water sources identified as cattle feeding and watering sites. Answers to "deer incursion" survey questions indicated that deer were seen on the premises of $100 \%$ of the farms identified. Ninety-two percent of respondents observed deer in pastures, 50\% observed evidence of deer feeding on hay intended for cattle, and $42 \%$ observed evidence of deer drinking from open water sources on the farms. Electric (75\%) and barbed wire (42\%) fencing was used on these cattle farms, but feed was only stored in "deer proof" facilities on $25 \%$ of the farms surveyed.

Dairy cattle operations generally maintained their cattle inside housing more than $50 \%$ of the time, fed their cattle 
inside, and used hay feeders; however, cattle had access to open water and hay was stored outside and unprotected on many of the premises investigated.

4.1.2. Wildlife Bovine TB Transmission Sites. The investigations of wildlife areas were performed in the summer and spring. In the spring and summer months, particular wildlife management practices that would facilitate the indirect transmission of bovine TB were not observed with the exception of the identification of small fields in wooded areas planted with grass forages to attract deer and a limited number of empty deer feeding stations which would likely have been active in winter.

4.2. Detection of M. bovis in the Environment: Agent-Related Factors. Properties of $M$. bovis contribute to difficulties associated with isolating the organism from environmental substrates. M. bovis is particularly difficult to culture. The necessity of a bactericidal decontamination step, coupled with the cording behavior and natural buoyancy of $M$. bovis, reduces the success of mycobacterial culture methods $[17,20]$. The additional presence of large numbers of saprophytic bacteria, molds, and other infectious organisms in environmental samples further interferes with the sensitivity of detection of M. bovis by bacterial culture. Attempts were made to improve the success of isolating $M$. bovis with bacterial culture methods by processing specimens with CB18 TB Culture Kit with Lytic Decon II (Integrated Research Technology, LLC, Quest Diagnostics Inc., Baltimore, Md, USA). Although M. bovis was not isolated, other mycobacterial species were successfully identified from environmental substrates collected suggesting that the techniques used were capable of detecting mycobacterial species from environmental samples in the presence of other competing microbes.

Culture contamination, an overgrowth of mold and nonmycobacterial species, affected our attempts to isolate M. bovis from approximately $25 \%$ of the samples collected. Although no significant associations were found between contamination rates and sample substrate type, the distribution of contamination in samples suggested that soil, vegetation samples, and those mixed with cattle manure were more likely to produce contaminated mycobacterial culture results. These data indicate that the sensitivity of isolation of $M$. bovis from these particular substrates types may be further reduced.

The challenges associated with detection of M. bovis in environmental substrates has been cited as a potential cause of failure to isolate M. bovis from environmental substrates from other areas identified as sites of natural transmission of bovine TB in Michigan. These include a captive white-tailed deer facility [21] and one of the first cattle farms identified as TB positive in the current outbreak of $M$. bovis in Michigan (Kaneene, personal communication). M. bovis has been isolated from environmental substrates contaminated in the course of experimental transmission studies among deer [22, 23] and between deer and cattle [24]; however, even under these "ideal" circumstances, success has been intermittent.
4.3. Detection of M. bovis in the Environment: Host Related Factors. One of the limitations of opportunistic environmental sampling of bovine TB-positive cattle herds and identified wildlife bovine TB transmission areas is that a time lag likely exists between the time at which the $M$. bovis shedding animal (cattle or deer) was present on the premises and the time of sample collection. This time lag is likely exacerbated by intermittent shedding of $M$. bovis from both infected deer [23] and infected cattle $[25,26]$. The probability of collecting an environmental sample from an identified bovine TB transmission site in the time period the infected animal is present and at a time when it is shedding M. bovis may be very low.

The denning behavior and patterns of movement of other wildlife reservoirs of bovine TB, primarily brushtail possums (Trichosurus vulpecula) in New Zealand [27] and European badgers (Meles meles) in Ireland and Great Britain [28, 29], allow for a closer approximation of the opportunities for their potential direct and indirect contact with cattle on bovine TB-affected farms. Although somewhat predictable, free-ranging white-tailed deer have much larger home ranges and their presence on cattle farms is more transient [30]. The behavior of potentially bovine TB-infected white-tailed deer does not allow for a fine level of targeted sampling of environmental substrates for the detection of M. bovis.

4.4. Detection of M. bovis in the Environment: LandscapeRelated Factors. Efforts to isolate M. bovis in other regions have yielded similar results when samples were collected under natural disease transmission conditions [31]. Researchers interested in the persistence of $M$. bovis in the environment have turned to experimental inoculation studies and an assessment of the conditions that support or inhibit M. bovis survival [27, 32-39]. This is due primarily to the difficulty of identifying the exact location of M. bovis contamination over what is often a very large potentially contaminated site. This study faced the same challenge. Financial and time constraints limited the number and volume of environmental substrates that could be collected and processed from sites potentially contaminated with $M$. bovis. These constraints limited the total surface area of both bovine TB-positive farms and wildlife areas that could be sampled effectively.

This field investigation of bovine TB transmission sites confirmed the findings of earlier studies that have identified environmental and cattle farm management practices [12] in northeast Michigan that may facilitate indirect interspecies transmission of bovine TB between deer and cattle. Investigations of wildlife $\mathrm{TB}$ transmission areas also produced evidence of deer feeding and baiting practices that have been identified by other authors as likely contributing to the indirect transmission of bovine TB among white-tailed deer $[1,8,9,13]$. The failure to isolate $M$. bovis from environmental substrates collected from bovine TB-positive cattle farms and wildlife areas was likely due to agent, host, and landscape factors that contribute to the difficulty of identifying specific sites of $M$. bovis contamination and recovering $M$. bovis from environmental substrates. 


\section{Acknowledgments}

This research was support by the United States Department of Agriculture, National Research Institute (Bovine Tuberculosis-Special Grant), the Michigan Department of Agriculture, Animal Industry Division, the United States Department of Agriculture, Animal and Plant Health Inspection Service, Wildlife Services, the Center for Comparative Epidemiology, and the Department of Large Animal Clinical Sciences, College of Veterinary Medicine, Michigan State University. Kathleen Gray and Desiree Oliver provided field and laboratory support. John Baker provided mentorship and overall guidance. The study would not have been possible without the cooperation and assistance of Michigan cattle farmers and field staff from the Michigan Department of Natural Resources and the USDA/APHIS Wildlife Services.

\section{References}

[1] S. M. Schmitt, S. D. Fitzgerald, T. M. Cooley et al., "Bovine tuberculosis in free-ranging white-tailed deer from Michigan," Journal of Wildlife Diseases, vol. 33, no. 4, pp. 749-758, 1997.

[2] Animal Industry Division, Michigan Department of Agriculture, 2010.

[3] S. M. Schmitt, D. J. O'Brien, C. S. Bruning-Fann, and S. D. Fitzgerald, "Bovine tuberculosis in Michigan wildlife and livestock," Annals of the New York Academy of Sciences, vol. 969, pp. 262-268, 2002.

[4] D. L. Whipple, J. L. Jarnagin, and J. B. Payeur, "DNA fingerprinting of Mycobacterium bovis isolates from animals in northeast Michigan," in Proceedings of the 9th International Symposium of the World Association of Veterinary Laboratory Diagnosticians, World Association of Veterinary Laboratory Diagnosticians, College Station, Tex, USA, 1999.

[5] D. J. O’Brien, S. M. Schmitt, S. D. Fitzgerald, D. E. Berry, and G. J. Hickling, "Managing the wildlife reservoir of Mycobacterium bovis: the Michigan, USA, experience," Veterinary Microbiology, vol. 112, no. 2-4, pp. 313-323, 2006.

[6] D. J. O’Brien, S. M. Schmitt, J. S. Fierke et al., "Epidemiology of Mycobacterium bovis in free-ranging white-tailed deer, Michigan, USA, 1995-2000," Preventive Veterinary Medicine, vol. 54, no. 1, pp. 47-63, 2002.

[7] T. J. DeLiberto, K. C. Vercauteren, and G. W. Witmer, "The Ecology of Mycobacterium bovis in Michigan," in Activities Report and Conference Proceedings, Michigan Bovine Tuberculosis Eradication Project, Lansing, Mich, USA, 2004.

[8] G. J. Hickling, "Dynamics of bovine tuberculosis in wild white-tailed deer in Michigan," Wildlife Division Report 3363, Michigan Department of Natural Resources, 2002.

[9] D. J. O’Brien, S. M. Schmitt, S. D. Fitzgerald, D. E. Berry, and G. J. Hickling, "Managing the wildlife reservoir of Mycobacterium bovis: the Michigan, USA, experience," Veterinary Microbiology, vol. 112, no. 2-4, pp. 313-323, 2006.

[10] USDA, A., Veterinary Services, Bovine Tuberculosis Eradication: Uniform Methods and Rules Effective January 1, 2005, United States Department of Agriculture, Washington, DC, USA, 2004.

[11] G. Witmer, A. E. Fine, J. Glonfriddo et al., "Epizootiologic survey of Mycobacterium bovis in wildlife and farm environments in northern michigan," Journal of Wildlife Diseases, vol. 46, no. 2, pp. 368-378, 2010.
[12] J. B. Kaneene, C. S. Bruning-Fann, L. M. Granger, R. Miller, and B. A. Porter-Spalding, "Environmental and farm management factors associated with tuberculosis on cattle farms in northeastern Michigan," Journal of the American Veterinary Medical Association, vol. 221, no. 6, pp. 837-842, 2002.

[13] R. Miller, J. B. Kaneene, S. D. Fitzgerald, and S. M. Schmitt, "Evaluation of the influence of supplemental feeding of whitetailed deer (Odocoileus virginianus) on the prevalence of bovine tuberculosis in the Michigan wild deer population," Journal of Wildlife Diseases, vol. 39, no. 1, pp. 84-95, 2003.

[14] A. E. Fine, "The role of indirect transmissoin in the epidemiology of bovine tuberculoisis in cattle and white-tailed deer in Michigan," in Large Animal Clinical Sciences, p. 157, Michigan State University, East Lansing, Mich, USA, 2006.

[15] C. G. Thornton, K. M. Maclellan, T. L. Brink et al., "Novelmethod for processing respiratory specimens for detection of mycobacteria by using C18-carbohxypropylbetaine: blinded study," Journal of Clinical Microbiology, vol. 36, no. 7, pp. 1996-2003, 1998.

[16] C. G. Thornton, K. M. MacLellan, T. L. Brink, D. M. Wolfe, O. J. Llorin, and S. Passen, "Processing respiratory specimens with C18-carboxypropylbetaine: development of a sediment resuspension buffer that contains lytic enzymes to reduce the contamination rate and lecithin to alleviate toxicity," Journal of Clinical Microbiology, vol. 36, no. 7, pp. 2004-2013, 1998.

[17] P. T. Kent and G. P. Kubica, Public Health Mycobacteriology: A Guide for Level III Laboratory, Public Health Service, Centers for Disease Control, U.S. Department of Health and Human Services, Atlanta, Ga, USA, 1985.

[18] C. Thoen and B. Bloom, "Pathogenesis of Mycobacterium bovis," in Mycobacterium bovis Infection in Animals and Humans, C.O. Thoen and J. H. Steele, Eds., pp. 3-14, Iowa State University Press, Ames, Iowa, USA, 1995.

[19] M. V. Palmer, D. L. Whipple, and S. C. Olsen, "Development of a model of natural infection with Mycobacterium bovis in white-tailed deer," Journal of Wildlife Diseases, vol. 35, no. 3, pp. 450-457, 1999.

[20] D. M. Yajko, C. Wagner, V. J. Tevere, T. Kocagoz, W. K. Hadley, and H. F. Chambers, "Quantitative culture of Mycobacterium tuberculosis from clinical sputum specimens and dilution endpoint of its detection by the Amplicor PCR assay," Journal of Clinical Microbiology, vol. 33, no. 7, pp. 1944-1947, 1995.

[21] M. V. Palmer, D. L. Whipple, J. B. Payeur et al., "Naturally occurring tuberculosis in white-tailed deer," Journal of the American Veterinary Medical Association, vol. 216, no. 12, pp. 1921-1924, 2000.

[22] M. V. Palmer, W. R. Waters, and D. L. Whipple, "Shared feed as a means of deer-to-deer transmission of Mycobacterium bovis," Journal of Wildlife Diseases, vol. 40, no. 1, pp. 87-91, 2004.

[23] M. V. Palmer, D. L. Whipple, and W. R. Waters, "Experimental deer-to-deer transmission of Mycobacterium bovis," American Journal of Veterinary Research, vol. 62, no. 5, pp. 692-696, 2001.

[24] M. V. Palmer, W. R. Waters, and D. L. Whipple, "Investigation of the transmission of Mycobacterium bovis from deer to cattle through indirect contact," American Journal of Veterinary Research, vol. 65, no. 11, pp. 1483-1489, 2004.

[25] A. V. Goodchild and R. S. Clifton-Hadley, "Cattle-to-cattle transmission of Mycobacterium bovis," Tuberculosis, vol. 81, no. 1-2, pp. 23-41, 2001.

[26] S. D. Neill, J. Hanna, J. J. O’Brien, and R. M. McCracken, "Excretion of Mycobacterium bovis by experimentally infected cattle," Veterinary Record, vol. 123, no. 13, pp. 340-343, 1988. 
[27] R. Jackson, G. W. de Lisle, and R. S. Morris, "A study of the environmental survival of Mycobacterium bovis on a farm in New Zealand," New Zealand Veterinary Journal, vol. 43, pp. 346-352, 1995.

[28] R. M. Anderson and W. Trewhella, "Population dynamics of the badger (Meles meles) and the epidemiology of bovine tuberculosis (Mycobacterium bovis)," Philosophical transactions of the Royal Society of London. Series B, vol. 310, no. 1145, pp. 327-381, 1985.

[29] M. R. Hutchings and S. Harris, "Effects of farm management practices on cattle grazing behaviour and the potential for transmission of bovine tuberculosis from badgers to cattle," Veterinary Journal, vol. 153, no. 2, pp. 149-162, 1997.

[30] M. Garner, "Movement patterns and behavior at winter feeding and fall baiting stations in a population of white-teailed deer infected with bovine tuberculosis in the northeastern Lower Peninsula of Michigan," 2001.

[31] S. D. Pillai, K. W. Widmer, L. J. Ivey et al., "Failure to identify non-bovine reservoirs of Mycobacterium bovis in a region with a history of infected dairy-cattle herds," Preventive Veterinary Medicine, vol. 43, no. 1, pp. 53-62, 2000.

[32] B. J. Duffield and D. A. Young, "Survival of Mycobacterium bovis in defined environmental conditions," Veterinary Microbiology, vol. 10, no. 2, pp. 193-197, 1984.

[33] T. W. A. Little, P. F. Naylor, and J. W. Wilesmith, "Laboratory study of Mycobacterium bovis infection in badgers and calves," Veterinary Record, vol. 111, no. 24, pp. 550-557, 1982.

[34] E. C. G. Maddock, "Studies on the survival time of the bovine tubercle bacillus in soil, soil and dung, in dung and on grass, with experiments on the preliminary treatment of infected organic matter and the cultivation of the organism," Journal of Hygiene, vol. 33, pp. 103-117, 1933.

[35] E. C. G. Maddock, "Further studies on the survival time of the bovine tubercle bacillus in soil, soil and dung, in dung and on grass, with experiments on feeding guinea-pigs and calves on grass artificially infected with bovine tubercle bacilli," Journal of Hygiene, vol. 34, pp. 372-379, 1934.

[36] E. C. G. Maddock, "Experiments on the infectivity for healthy calves on bovine tubercle bacilli discharged in dung upon pasture. Part 1. From tubercular calves fed with emulsion of tubercle bacilli 1934-5. Part 2. From tubercular cows passing tubercle bacilli in their dung 1935-6," Journal of Hygiene, vol. 36, pp. 594-601, 1936.

[37] M. Tanner and A. L. Michel, "Investigation of the viability of M. bovis under different environmental conditions in the Kruger National Park," Onderstepoort Journal of Veterinary Research, vol. 66, no. 3, pp. 185-190, 1999.

[38] S. R. Williams and W. A. Hoy, "The viability of B. tuberculosis (bovinus) on pasture land, in stored faeces and in liquid manure," Journal of Hygiene, vol. 30, pp. 413-419, 1930.

[39] C. Wray, "Survival and spread of pathogenic bacteria of veterinary importance within the environment," Veterinary Bulletin, vol. 45, pp. 543-550, 1975. 

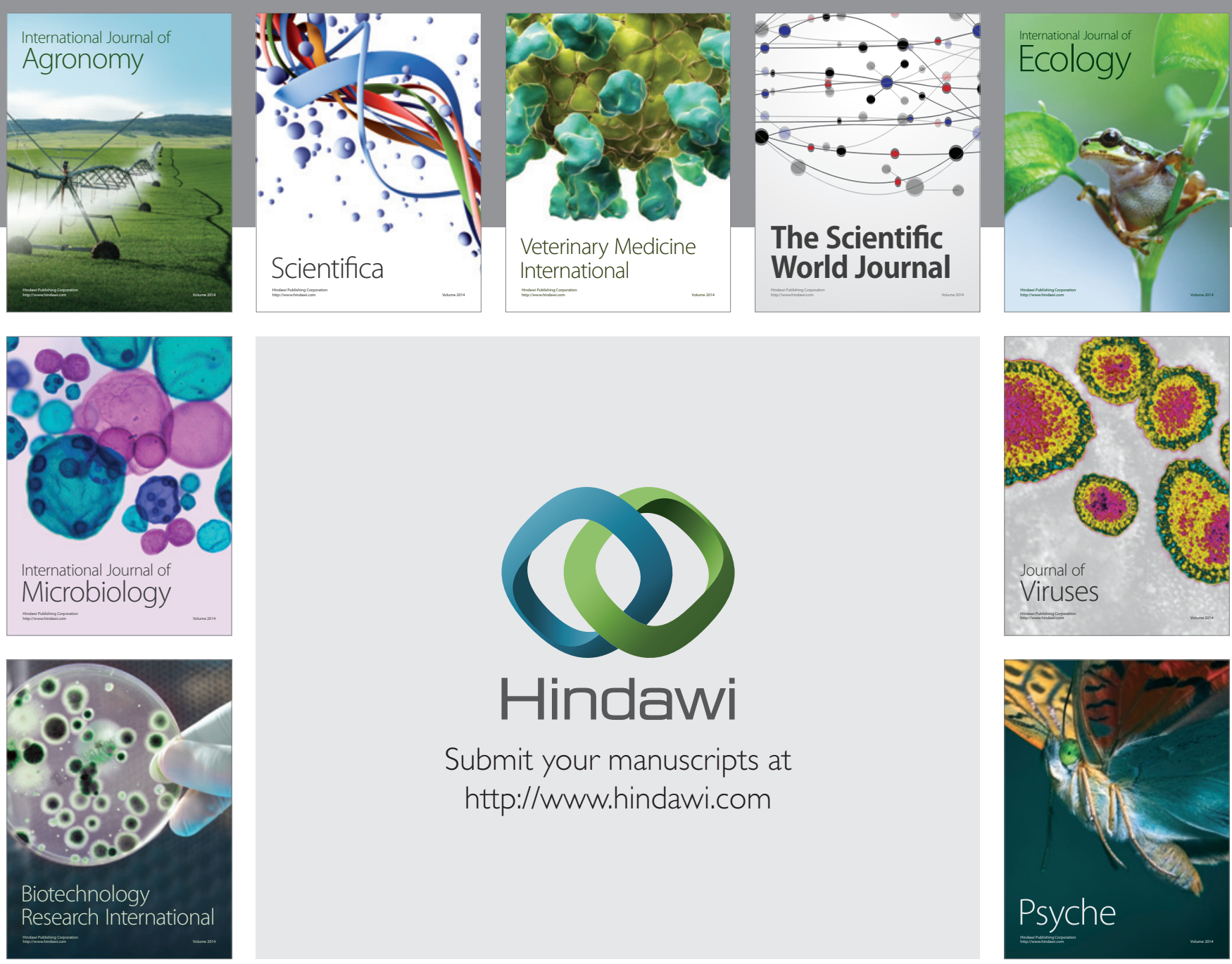

Submit your manuscripts at http://www.hindawi.com
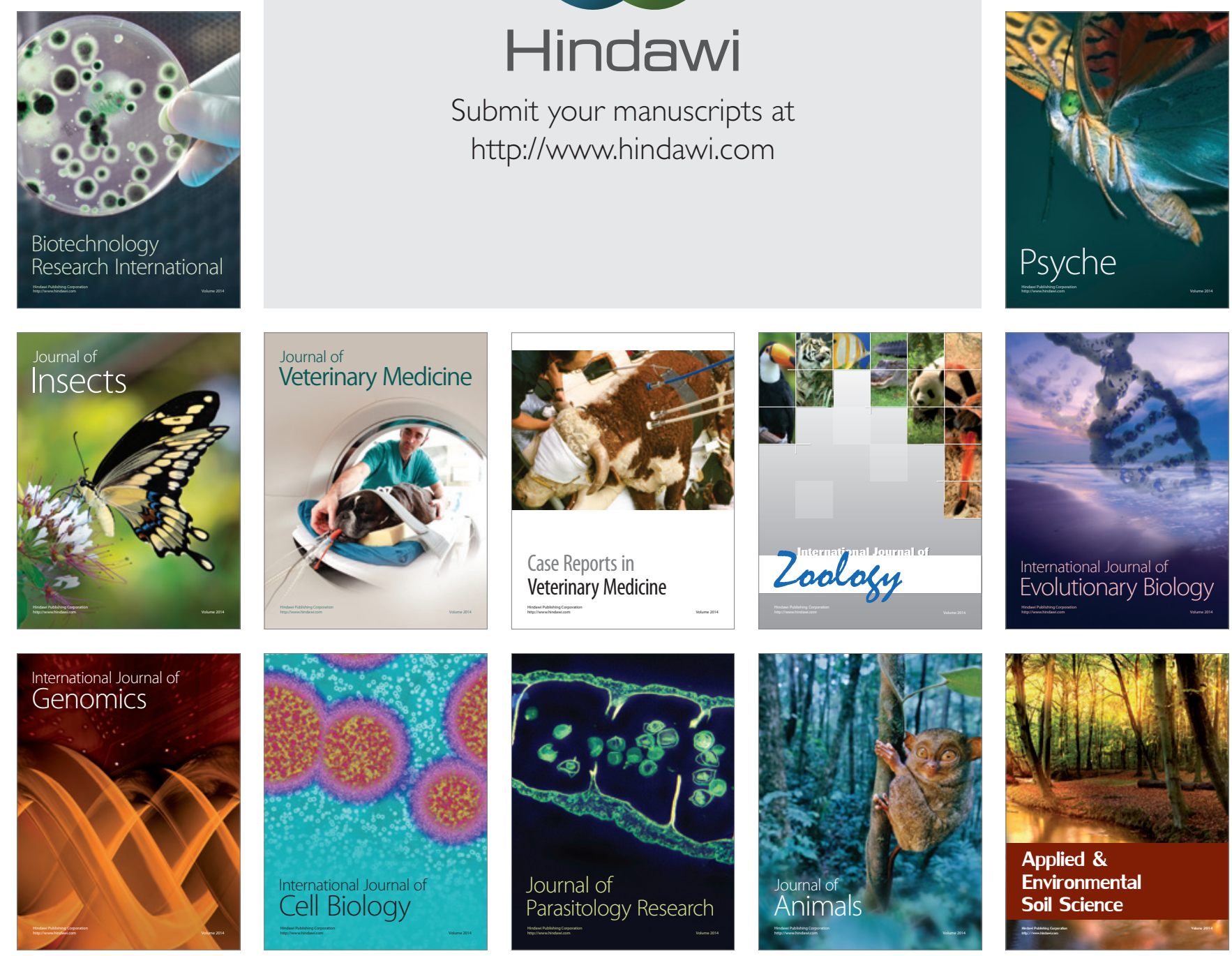